\title{
Non-linear Optical Properties of Group 10 Metal Alkynyls and their Polymers
}

\author{
Werner J. Blau, ${ }^{a}$ Hugh J. Byrne, ${ }^{a}$ David J. Cardin ${ }^{b}$ and Andrew P. Davey ${ }^{b}$ \\ ${ }^{a}$ Department of Pure and Applied Physics and ${ }^{b}$ Department of Chemistry, Trinity College, \\ University of Dublin, Dublin 2, Ireland
}

\begin{abstract}
Conjugated diacetylene and phenylacetylene systems incorporating Group 10 transition-metal complexes have been obtained via lithium acetylide intermediates. In the UV-VIS spectra, the positioning of the longestwavelength absorption shows a strong dependence on the incorporated metal. Polymers of both the transnickel and the trans-platinum bisphosphine diacetylide $\left[\mathrm{M}\left(\mathrm{PR}_{3}\right)_{2}(\mathrm{C} \equiv \mathrm{C}-\mathrm{C} \equiv \mathrm{CH})_{2}\right](\mathrm{M}=\mathrm{Ni}$, or Pt; $\mathrm{R}=$ alkyl group) were synthesised. UV absorption spectra show a significant shift of the absorption maxima from those of the monomers, towards longer wavelengths, consistent with an increase in the degree of electron delocalisation per monomer unit. The third-order non-linear optical properties of these materials in solution were examined using the method of self-diffraction from laser-induced gratings with 70 ps pulses of wavelength $1.064 \mu \mathrm{m}$. In the case of the monomer solutions, intensity dependences of the diffraction efficiencies show the influence of the proximity of a three-photon resonance at low concentrations. At higher concentration the influence of this resonance is not apparent. Among the materials synthesised, a clear trend, down the group, is seen, the hyperpolarisabilities decreasing with increasing atomic number of the metal. Measured hyperpolarisabilities are compared with those of enyne oligomer solutions and are found to be substantially higher. Metal-containing polymeric systems show an intensity dependence that is characteristic of a pure third-order process. Molecular hyperpolarisabilities show trends similar to those of the monomeric species. Both polymers possess a non-linearity higher than that of equivalent polydiacetylene solutions.
\end{abstract}

Keywords: Non-linear optical material; Transition-metal complex; Conjugated polymer

In the search for materials that might be useful for all-optical switching, organic conjugated polymers have received much attention. ${ }^{1}$ Their delocalised $\pi$-electron backbones exhibit sizeable non-linear optical susceptibilities with ultrafast response and recovery times. ${ }^{2}$ In addition, their structural and electronic properties can be varied chemically and the fact that they are easily processed renders them potentially useful in integrated optical technologies.

Over the past decade, much research has been carried out in this field and the result of intensive synthetic efforts is a range of $\pi$-conjugated organic polymeric systems, within which polydiacetylenes have shown particular promise with off-resonant non-linearities as high as $10^{-10}$ esu. $\dagger^{3}$ It is important, however, to consider the minimum non-linearity required for realistic application to optical switching. This has been estimated to be $>10^{-9} \mathrm{esu}^{4}$ This value may have been achieved, ${ }^{5}$ but not exceeded using an electronic non-linearity. Furthermore, studies of the dependence of the molecular hyperpolarisability $(\gamma)$ on chain length in enyne oligomers indicate that it does not extrapolate to the polymer which exhibits a non-linearity corresponding to a chain length of only $7-10$ repeat units. ${ }^{6}$ This saturation of the material non-linearity may be linked with strong imaginary components of the non-linearity, associated with a strong electronlattice coupling, characteristic of these quasi one-dimensional systems. $^{?}$

These results suggest that greater hyperpolarisabilities may not be achieved simply by increasing the electron density per monomer unit. For example, chemical doping of polymers has been observed to lower the non-linear optical response. ${ }^{8}$ Therefore, consideration must be given to ways of modifying the electronic and lattice configurations. Modification of the electronic configuration of a polymer backbone must be

$\dagger 1 \mathrm{esu} \equiv 1.4 \times 10^{-8} \mathrm{~m}^{2} \mathrm{~V}^{-2}$ accommodated by the lattice to avoid charge localisation and a break-up of the backbone configuration. ${ }^{4}$

Incorporation of transition metals into conjugated organic systems has been reported for other purposes. The presence of polarisable low oxidation state metals having occupied $\mathrm{d}$ orbitals in the conjugated backbone should increase the hyperpolarisability. In this study, the effect on the non-linear optical properties of incorporating such metals into diacetylenic systems is examined. The metals are incorporated in a square-planar geometry leading to a linear backbone, which should result in increased conjugation. The variation of the hyperpolarisabilities with the metal have been studied and the results compared with those for enyne oligomers and polydiacetylenes.

\section{Experimental}

Chemical Synthesis and Characterisation

The complexes trans- $\left[\mathrm{M}(\mathrm{PhC} \equiv \mathrm{C})_{2}\left(\mathrm{PEt}_{3}\right)_{2}\right],(\mathrm{M}=\mathrm{Ni}, \mathrm{Pd}$, or $\mathrm{Pt}$ ), were first synthesised by Chatt and Shaw ${ }^{9,11}$ and Calvin and Coates, ${ }^{10}$ and trans- $\left[(\mathrm{HC} \equiv \mathrm{C}-\mathrm{C} \equiv \mathrm{C})_{2} \mathrm{M}\left(\mathrm{PEt}_{3}\right)_{2}\right]$ by Hagihara et al. ${ }^{12}$ In these reports sodium acetylide intermediates were prepared in liquid ammonia. We have adopted a more convenient procedure, affording these complexes in reasonable to good yields, employing lithium acetylides, readily obtainable in ether from the appropriate acetylene and $\mathrm{n}$-butyllithium. All reactions were performed under an $\mathrm{N}_{2}$ atmosphere, solvents were purified by standard methods and distilled and degassed before use. $\mathrm{HC} \equiv \mathrm{C}-\mathrm{C} \equiv \mathrm{CH}$ was prepared as published. ${ }^{13}$

trans- $\left[\mathrm{Ni}(\mathrm{C} \equiv \mathrm{CPh})_{2}\left(\mathrm{PEt}_{3}\right)_{2}\right]$ was made by a modification of the method of Chatt and Shaw. To a stirred solution of $\left[\mathrm{Ni}\left(\mathrm{PEt}_{3}\right)_{2} \mathrm{Cl}_{2}\right],(2.69 \mathrm{~g}, 7.35 \mathrm{mmol})$ in ether $\left(30 \mathrm{~cm}^{3}\right)$ was added dropwise a solution of $\mathrm{PhC} \equiv \mathrm{CLi}(14.7 \mathrm{mmol})$ in ether $\left(30 \mathrm{~cm}^{3}\right)$ at $30^{\circ} \mathrm{C}$ over a period of $30 \mathrm{~min}$. A change from deep red to orange/brown was observed. Following the 
additions, the solution was allowed to warm to room temperature. Removal of solvent under vacuum yielded a brown oil which was purified by silica column chromatography (eluent hexane) yielding an orange/yellow solution which, when reduced to low volume, yielded the product as orange needles ( $2.63 \mathrm{~g}, 71 \%$ ), m.p. $148-151{ }^{\circ} \mathrm{C}$. IR (KBr disc): $2961 \mathrm{sh}, 2928 \mathrm{sh}$, $2122 \mathrm{sh}, 1587 \mathrm{sh}, 1021 \mathrm{sh}, 595 \mathrm{sh}$ and $573 \mathrm{~m} \mathrm{~cm}^{-1} .{ }^{1} \mathrm{H}$ NMR $\delta$ (solvent $\mathrm{CDCl}_{3}$; standard $\left.\mathrm{SiMe}_{4}\right) 1.38(\mathrm{q}), 1.59(\mathrm{t})$ and $7.22(\mathrm{~m})$. UV $\lambda_{\max }\left(\mathrm{CHCl}_{3}\right) 370 \mathrm{~nm}\left(\varepsilon 4.0 \times 10^{5} \mathrm{dm}^{3} \mathrm{~mol}^{-1} \mathrm{~cm}^{-1}\right)$.

The following were similarly prepared. trans$\left[\mathrm{Pd}(\mathrm{C} \equiv \mathrm{CPh})_{2} \mathrm{Pd}\left(\mathrm{PEt}_{3}\right)_{2}\right]$ using cis-[Pd($\left.\left(\mathrm{PEt}_{3}\right)_{2} \mathrm{Cl}_{2}\right],(2.03 \mathrm{~g}$, $6.22 \mathrm{mmol})$ and $\mathrm{PhC} \equiv \mathrm{CLi},(1.34 \mathrm{~g}, 12.44 \mathrm{mmol})$ in ether: yield $1.62 \mathrm{~g}, 57 \%$; m.p. $163-164{ }^{\circ} \mathrm{C}$. IR( $\mathrm{KBr}$ disc): $2965 \mathrm{sh}$, $2931 \mathrm{sh}, 2118 \mathrm{sh}, 1988 \mathrm{sh}, 1597 \mathrm{sh}, 1486 \mathrm{sh}, 1034 \mathrm{sh}, 766 \mathrm{~m}, 757 \mathrm{~m}$, $581 \mathrm{~m}$ and $543 \mathrm{~m} \mathrm{~cm}^{-1} .{ }^{1} \mathrm{H}$ NMR $\delta$ (solvent $\mathrm{CDCl}_{3}$; standard $\left.\mathrm{SiMe}_{4}\right), 1.32(\mathrm{q}), 1.51(\mathrm{t})$ and $7.18(\mathrm{~m})$. UV $\lambda_{\max }\left(\mathrm{CHCl}_{3}\right) 370 \mathrm{~nm}$ $\left(\varepsilon 3.71 \times 10^{3} \mathrm{dm}^{3} \mathrm{~mol}^{-1} \mathrm{~cm}^{-1}\right)$.

trans $-\left[\mathrm{Pt}(\mathrm{C} \equiv \mathrm{CPh})_{2}\left(\mathrm{PEt}_{3}\right)_{2}\right] \quad$ using $\quad$ cis- $\left[\mathrm{Pt}\left(\mathrm{PEt}_{3}\right)_{2} \mathrm{Cl}_{2}\right]$ $(1.27 \mathrm{~g}, 3.3 \mathrm{mmol})$ and $\mathrm{PhC} \equiv \mathrm{CLi}(0.7 \mathrm{~g}, 6.6 \mathrm{mmol})$ in ether: yield $1.32 \mathrm{~g}, 74 \%$; m.p. $186-188^{\circ} \mathrm{C}$. IR( $\mathrm{KBr}$ disc): $2971 \mathrm{sh}$, $2935 \mathrm{sh}, 2177 \mathrm{sh}, 1979 \mathrm{sh}, 1601 \mathrm{sh}, 1483 \mathrm{sh}, 1027 \mathrm{sh}, 752 \mathrm{~m}, 585 \mathrm{~m}$ and $552 \mathrm{~m} \mathrm{~cm}^{-1} .{ }^{1} \mathrm{H}$ NMR $\delta$ (solvent $\mathrm{CDCl}_{3}$; standard $\mathrm{SiMe}_{4}$ ), $1.34(\mathrm{q}), \quad 1.55(\mathrm{t})$ and $7.21(\mathrm{~m})$. UV $\lambda_{\max }\left(\mathrm{CHCl}_{3}\right) 332 \mathrm{~nm}$ $\left(\varepsilon 1.36 \times 10^{4} \mathrm{dm}^{3} \mathrm{~mol}^{-1} \mathrm{~cm}^{-1}\right)$.

trans $-\left[\mathrm{Ni}(\mathrm{C} \equiv \mathrm{C}-\mathrm{C} \equiv \mathrm{CH})_{2}\left(\mathrm{PEt}_{3}\right)_{2}\right] \quad$ using cis$\left[\mathrm{Ni}\left(\mathrm{PEt}_{3}\right)_{2} \mathrm{Cl}_{2}\right](2.29 \mathrm{~g}, 5.81 \mathrm{mmol})$ and $\mathrm{HC} \equiv \mathrm{C}-\mathrm{C} \equiv \mathrm{CLi}$ $(1.25 \mathrm{~g}, \quad 11.62 \mathrm{mmol})$ in ether: yield $1.56 \mathrm{~g}, 68 \%$; m.p. $140-142{ }^{\circ} \mathrm{C}$. IR ( $\mathrm{KBr}$ disc): 3210sh, 2970sh, 2938sh, $2105 \mathrm{sh}, 1990 \mathrm{sh}, 1591 \mathrm{sh}, 1478 \mathrm{sh}, 1035 \mathrm{sh}, 770 \mathrm{~m}, 588 \mathrm{~m}$ and $570 \mathrm{~m} \mathrm{~cm}^{-1}$. ${ }^{1} \mathrm{H}$ NMR $\delta$ (solvent $\mathrm{CDCl}_{3}$; standard $\mathrm{SiMe}_{4}$ ), 1.39(q), $1.61(\mathrm{t})$ and 6.12(s). UV $\lambda_{\max }\left(\mathrm{CHCl}_{3}\right) \quad 336 \mathrm{~nm}$ ( $\left.6.54 \times 10^{3} \mathrm{dm}^{3} \mathrm{~mol}^{-1} \mathrm{~cm}^{-1}\right)$.

trans $-\left[\mathrm{Pd}(\mathrm{C} \equiv \mathrm{C}-\mathrm{C} \equiv \mathrm{CH})_{2}\left(\mathrm{PEt}_{3}\right)_{2}\right]$ using cis$\left[\mathrm{Pd}\left(\mathrm{PEt}_{3}\right)_{2} \mathrm{Cl}_{2}\right],(2.03 \mathrm{~g}, 6.22 \mathrm{mmol})$ and $\mathrm{HC} \equiv \mathrm{C}-\mathrm{C} \equiv \mathrm{CLi}$, $(1.34 \mathrm{~g}, 12.44 \mathrm{mmol})$ in ether: yield $1.97 \mathrm{~g}, 72 \%$; m.p. $98-99^{\circ} \mathrm{C}$. IR (KBr disc): $3225 \mathrm{sh}, 2975 \mathrm{sh}, 2934 \mathrm{sh}, 2122 \mathrm{sh}, 1991 \mathrm{sh}, 1597 \mathrm{sh}$, $1481 \mathrm{sh}, 1040 \mathrm{sh}, 773 \mathrm{~m}, 599 \mathrm{~m}$ and $593 \mathrm{~m} \mathrm{~cm}^{-1}$. ${ }^{1} \mathrm{H}$ NMR $\delta$ (solvent $\mathrm{CDCl}_{3}$; standard $\mathrm{SiMe}_{4}$ ) $1.30(\mathrm{q}), 1.52(\mathrm{t})$ and $6.21(\mathrm{~s})$. UV $\lambda_{\max }\left(\mathrm{CHCl}_{3}\right) 290 \mathrm{~nm}\left(\varepsilon 1.32 \times 10^{2} \mathrm{dm}^{3} \mathrm{~mol}^{-1} \mathrm{~cm}^{-1}\right)$.

trans $-\left[\mathrm{Pt}(\mathrm{C} \equiv \mathrm{C}-\mathrm{C} \equiv \mathrm{CH})_{2}\left(\mathrm{PEt}_{3}\right)_{2}\right] \quad$ using cis$\left[\mathrm{Pt}\left(\mathrm{PEt}_{3}\right)_{2} \mathrm{Cl}_{2}\right](1.16 \mathrm{~g}, 2.3 \mathrm{mmol})$ and $\mathrm{HC} \equiv \mathrm{C}-\mathrm{C} \equiv \mathrm{CLi}$ $(0.49 \mathrm{~g}, 4.60 \mathrm{mmol})$ in ether: yield $0.95 \mathrm{~g}, \quad 78 \%$; m.p. 121-123 ${ }^{\circ} \mathrm{C}$. IR ( $\mathrm{KBr}$ disc): 3221sh, 2971sh, 2931sh, $2138 \mathrm{sh}, 1994 \mathrm{sh}, 1602 \mathrm{sh}, 1476 \mathrm{sh}, 1047 \mathrm{sh}, 761 \mathrm{~m}, 576 \mathrm{~m}$ and $401 \mathrm{~m} \mathrm{~cm}^{-1}$. ${ }^{1} \mathrm{H}$ NMR $\delta$ (solvent $\mathrm{CDCl}_{3}$; standard $\mathrm{SiMe}_{4}$ ), $1.35(\mathrm{q}), \quad 1.55(\mathrm{t})$ and $6.29(\mathrm{~s})$. UV $\lambda_{\max }\left(\mathrm{CHCl}_{3}\right) \quad 318 \mathrm{~nm}$ $\left(\varepsilon 1.03 \times 10^{3} \mathrm{dm}^{3} \mathrm{~mol}^{-1} \mathrm{~cm}^{-1}\right)$.

The polymers $\left[-\mathrm{M}\left(\mathrm{PBu}_{3}\right)_{2}-\mathrm{C} \equiv \mathrm{C}-\mathrm{C} \equiv \mathrm{C}-\right)_{n}$ where $\mathrm{M}=\mathrm{Ni}$ or $\mathrm{Pt}$ were prepared by copper(I) coupling of the alkynyl with the dihalometal phosphine compound in diethylamine as described by Hagihara et al. ${ }^{14,15}$

\section{Non-linear Optical Studies}

The experimental method employed was that of Forced Light Scattering from Laser Induced Gratings, a technique that corresponds to a degenerate four-wave mixing process in the forward direction. ${ }^{16}$ The light source is an amplified, passively mode-locked $\mathrm{Nd}^{3+}$ :YAG laser emitting linearly polarised pulses of $50 \pm 25$ ps duration and of wavelength $i=1.064 \mu \mathrm{m}$ at a frequency of $3 \mathrm{~Hz}$. Peak powers of up to $50 \mathrm{MW}$ were readily available. The experimental method is described in detail elsewhere ${ }^{17}$ and the set-up is depicted schematically in Fig. 1. It is based on the interference at the sample of two spatially and temporally overlapped beams, producing a spatial modulation of the intensity-dependent refractive index of the material. This modulation acts as a diffraction grating from which the pulses may self-diffract. Under thin grating

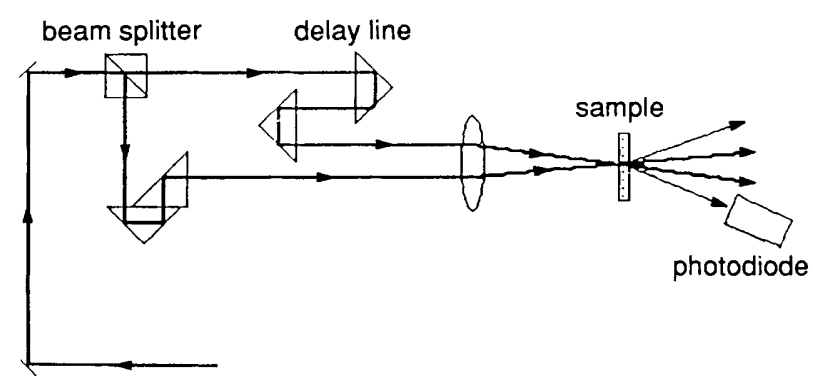

Fig. 1 Experimental set-up for self-diffraction technique

conditions, ${ }^{16}$ satisfied experimentally by keeping the angle between the two beams small $\left(<1^{\circ}\right)$, an expression relating the diffraction efficiency into the first order $(\eta)$, to the thirdorder material non-linearity may be derived:

$$
\left|\chi^{(3)}\right|=\frac{4 \varepsilon_{0} c n^{2} \lambda \sqrt{ } \eta}{3 \pi d I_{0}}
$$

where $c$ is the speed of light, $\varepsilon_{0}$ is the permittivity of free space, $n$ is the refractive index of the sample, $d$ is the sample thickness and $I_{0}$ is the input pulse intensity. In the experiments reported here, $d=1 \mathrm{~mm}$ and $n$ is taken to be the refractive index of the solvent, because of the low fractional volume of solute. Eqn. (1) holds for materials that are transparent at the operating wavelength.

It can be seen from eqn. (1) that verification of the presence of a true third-order non-linear process may be performed by monitoring the intensity dependence of the diffraction efficiency. For a true third-order process,

$$
\eta=\frac{I_{1}}{I_{0}} \propto I_{0}^{2}
$$

where $I_{1}$ is the intensity diffracted into the first order. Such a verification is important as fifth- and seventh-order processes, originating in two- and three-photon resonant enhancement of the material non-linearities, have been observed in organic conjugated materials. ${ }^{17,18}$

$\left|\chi^{(3)}\right|$ may have both real and imaginary components originating from the solute as well as a contribution from the solvent, $\chi^{(3)}{ }_{\text {solv }}$, which is purely real and positive in the organic solvents employed. ${ }^{19}$ For the concentration range used in this work the solute fractional volume is negligible. Hence

$$
\left|\chi^{(3)}\right|=\left[\left(\chi_{\text {solv }}^{(3)}+\operatorname{Re} \chi^{(3)}{ }_{\text {solu }}\right)^{2}+\left(\operatorname{Im} \chi_{\text {solu }}^{(3)}\right)^{2}\right]^{1 / 2}
$$

where $\operatorname{Re} \chi^{(3)}$ solu and $\operatorname{Im} \chi^{(3)}$ solu are the real and imaginary components of the solute non-linearity. By monitoring the concentration dependence of $\left|\chi^{(3)}\right|$, the contribution $\chi^{(3)}$ solv may be extracted and the magnitudes of $\operatorname{Re} \chi^{(3)}$ solu and $\operatorname{Im} \chi^{(3)}{ }_{\text {solu }}$ may be determined. Furthermore, the sign of $\operatorname{Re} \chi^{(3)}$ solu may be determined from the concentration dependence of the real part of $\left|\chi^{(3)}\right| .^{17}$

\section{Results and Discussion}

A series of solutions, of different concentrations, was made up in chloroform for each material. Maximum concentrations used were $2.7,10.3$ and $6.2 \mathrm{~g} \mathrm{dm}^{-3}$ for the nickel, palladium and platinum diacetylides and $1.4,2.1$ and $6.2 \mathrm{~g} \mathrm{dm}^{-3}$ for the nickel, palladium and platinum phenyl acetylides, respectively. Measurements of the diffraction efficiency as a function of pump intensity and polymer concentration were performed with calibrated photodiodes and a digital storage oscilloscope as described above.

At high concentrations the intensity dependence of the diffraction efficiency was found to be characteristic of a third- 
order non-linear optical process, as is that of the solvent. At low concentrations, however, all monomers exhibit a highorder intensity dependence, characteristic of a multiphoton resonant enhancement of the diffraction process. As an example, the concentration dependence of the order of the intensity dependence of the diffraction efficiency in trans$\left[\mathrm{Pt}(\mathrm{C} \equiv \mathrm{C}-\mathrm{C} \equiv \mathrm{CH})_{2}\left(\mathrm{PEt}_{3}\right)_{2}\right]$ solutions is shown in Fig. 2. A maximum intensity dependence of $I^{6}$, indicative of a seventhorder non-linear optical process, was observed. A similar intensity dependence is seen in polythiophene solutions, ${ }^{8}$ and may be identified as the result of a three-photon resonant enhancement of the diffraction process. Notably, a strong concentration dependence of this resonant enhancement has also been observed in polythiophene solutions, although it is not as pronounced as is seen in the present case. Such concentration dependence may be associated with concentration-dependent interchain coupling which causes a variation in backbone electron correlations, a strong determining factor in the positioning of multiphoton absorption levels. ${ }^{20}$ Whereas this behaviour has been frequently observed for polymers, our results indicate that aggregation also plays a significant role for these monomeric systems, producing effects (i.e. concentration and intensity dependence) analogous to those associated with interchain coupling in polymers. The observation of this multiphoton absorption at low concentrations is indicative of a reasonable degree of backbone electron correlation, suggesting a significant interaction of the metallic $d$ electrons with the organic $\pi$-conjugated system.

This concentration-dependent resonant enhancement of the molecular non-linearity complicates the interpretation. An example is shown in Fig. 3 for the concentration dependence of the diffraction efficiency of the trans$\left[\mathrm{Ni}(\mathrm{C} \equiv \mathrm{C}-\mathrm{C} \equiv \mathrm{CH})_{2}\left(\mathrm{PEt}_{3}\right)_{2}\right]$. The diffraction efficiency

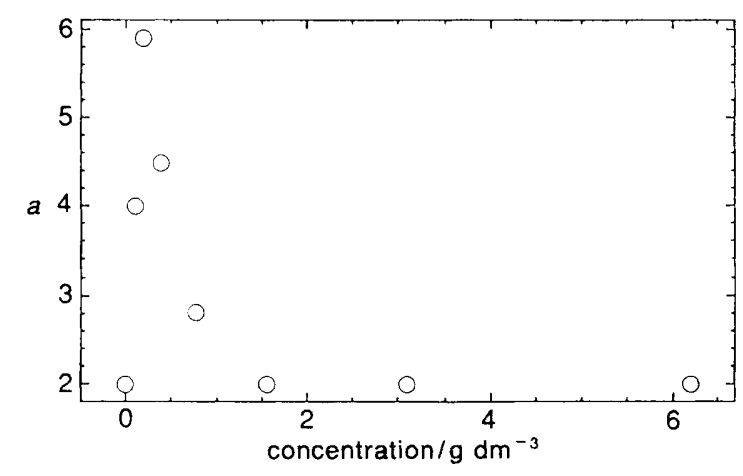

Fig. 2 Concentration dependence of the order $\left(I^{a}\right)$ of the intensity dependence of the diffraction efficiency for the trans$\left[\mathrm{Pt}(\mathrm{C} \equiv \mathrm{C}-\mathrm{C} \equiv \mathrm{CH})_{2}\left(\mathrm{PEt}_{3}\right)_{2}\right]$ solutions

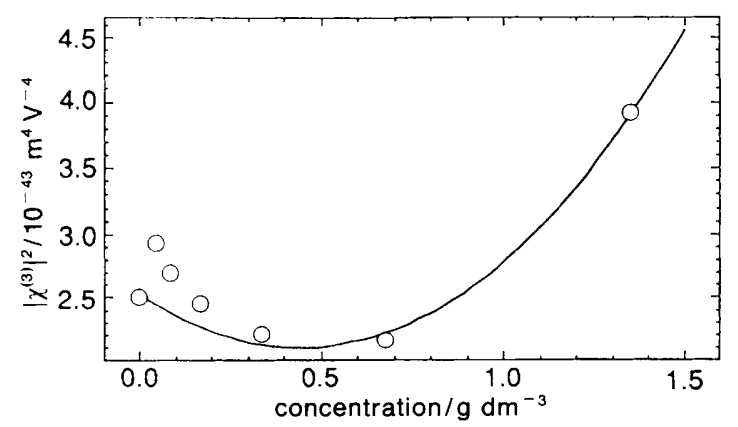

Fig. 3 Concentration dependence of the diffraction efficiency of the trans $-\left[\mathrm{Ni}(\mathrm{C} \equiv \mathrm{C}-\mathrm{C} \equiv \mathrm{CH})_{2}\left(\mathrm{PEt}_{3}\right)_{2}\right]$ solutions. Solid line is a fit to eqn. (3) in the region without three-photon resonance peaks sharply initially, under the influence of the three-photon resonance, but then falls markedly below the level of the solvent, and subsequently shows the expected parabolic dependence, see eqn. (3). An estimate of the molecular hyperpolarisability may be made by fitting this concentration dependence to the regions that show a purely third-order non-linearity. For a realistic comparison of the non-linearity with that of other materials, the third-order molecular hyperpolarisability, given by

$$
|\gamma|=\frac{\left|\chi^{(3)}\right|}{N_{\mathrm{A}} C L_{\mathrm{L}}^{4}}
$$

should be used, where $C$ is the molar concentration, $N_{\mathrm{A}}$ is Avogadro's number and $L_{\mathbf{L}}$ is the Lorentz local field factor, which for practical purposes is taken to be that of a spherical or randomly coiled molecule, and is given by ${ }^{21}$

$$
L_{\mathrm{L}}=\frac{n^{2}+2}{3}
$$

$|\gamma|$ may similarly be resolved into real and imaginary components, $\gamma_{R}$ and $\gamma_{1}$. The estimated values for the respective components of the molecular hyperpolarisabilities for each monomer are given in Table 1. A trend of increasing molecular hyperpolarisability with decreasing atomic number may be clearly seen for both sets of monomers, the phenyl acetylides giving larger values than the diacetylides. Indeed this is consistent with the increase in maximum absorption wavelength observed in the linear optical spectra.

Of particular interest is a comparison between the molecular hyperpolarisabilities of the metal-containing systems with organic materials. Fig. 4 shows a plot of $|\gamma|$ versus chain length for a series of enyne oligomers, ${ }^{6}$ which serve as model building blocks for polydiacetylenes. In this figure, the values measured for the metal diacetylide and phenyl acetylide monomers have also been plotted. Chain lengths for the metal-containing monomer systems are taken from X-ray crystallographic data [for the phenylethynyl monomers from ref. 22(a) and for the butadiynyls from ref. 22(b)]. It can be seen that all of the metal-containing systems possess a non-linearity which is substantially larger than for an enyne oligomer of equivalent length. Indeed, the hyperpolarisability of the nickel diacetylide is larger than that of the enyne hexamer. Apart from the influence at low concentrations of the three-photon absorption, qualitatively these materials behave similarly to the enyne oligomers. The sign of the real component of the non-linearity is negative, as in the case of enyne oligomers longer than the dimer. ${ }^{6}$ In addition, a strong contribution from imaginary components of the non-linearity is observed establishing the expected strong electron-vibration coupling.

As these results were promising we also examined the nickel and platinum polymers. Solutions of different concentrations were made, of maximum concentration 1.0 and $1.4 \mathrm{~g} \mathrm{dm}^{-3}$, respectively. The intensity dependence of the diffraction efficiency was monitored for each solution and, as is shown in Fig. 5, was found to be characteristic of a true third-order process for both polymers. The concentration dependence of the diffraction efficiency at fixed intensity is shown in Fig. 6. An initial decrease of the diffraction efficiency from that of the solvent is seen (indicative of a negative real component of the polymer non-linearity), followed by an increase. However, as the concentration is increased, the non-linearity falls below the parabolic dependence predicted by eqn. (3). A similar behaviour has been observed in a number of polymer solutions, including polydiacetylene-chloroform solutions, ${ }^{23}$ and may be attributed to concentration-dependent interchain interactions. Such interactions appear to decrease the monomeric hyperpolarisability. Efforts towards a qualitative under- 
Table 1 Measured hyperpolarisabilities of metal-containing systems and comparison with poly (4BCMU)

\begin{tabular}{|c|c|c|c|c|c|}
\hline system & molecular weight & $\lambda_{\max } / \mathrm{nm}$ & $\gamma_{\mathrm{R}} / \mathrm{m}^{5} \mathrm{~V}^{-2}$ & $\left|\gamma_{1}\right| / \mathrm{m}^{5} \mathrm{~V}^{-2}$ & $|\gamma| / \mathrm{m}^{5} \mathrm{~V}^{-2}$ \\
\hline NiDA & 344 & 336 & $-7.87 \times 10^{-44}$ & $1.72 \times 10^{-43}$ & $1.89 \times 10^{-43}$ \\
\hline PdDA & 392 & 290 & $-3.85 \times 10^{-44}$ & $9.19 \times 10^{-45}$ & $3.96 \times 10^{-44}$ \\
\hline PtDA & 480 & 318 & $-1.93 \times 10^{-44}$ & $7.71 \times 10^{-45}$ & $2.08 \times 10^{-44}$ \\
\hline $\mathrm{pNiDA}$ & 511 & 412 & $-2.63 \times 10^{-42}$ & $2.41 \times 10^{-42}$ & $3.57 \times 10^{-42}$ \\
\hline pPtDA & 647 & 364 & $-1.48 \times 10^{-42}$ & $1.74 \times 10^{-42}$ & $2.28 \times 10^{-42}$ \\
\hline NiPA & 497 & 370 & $-2.75 \times 10^{-43}$ & $1.46 \times 10^{-43}$ & $3.11 \times 10^{-43}$ \\
\hline PdPA & 545 & 370 & $-2.10 \times 10^{-43}$ & $3.39 \times 10^{-44}$ & $2.13 \times 10^{-43}$ \\
\hline PtPA & 633 & 332 & $-1.12 \times 10^{-43}$ & $2.15 \times 10^{-44}$ & $1.14 \times 10^{-43}$ \\
\hline p4BCMU & 480 & 480 & - & - & $2.00 \times 10^{-42}$ \\
\hline
\end{tabular}

DA, diacetylide; PA, phenyl acetylide; p, poly; 4BCMU, 4-(butoxycarbonylmethylurethane) diacetylene.

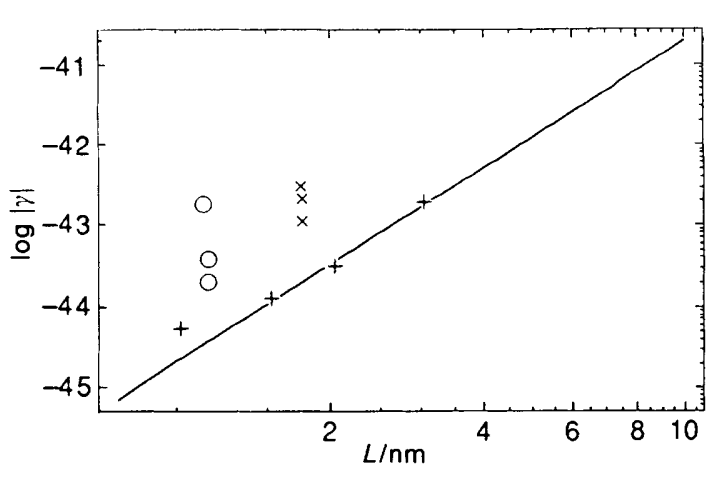

Fig. 4 Comparison of hyperpolarisabilities of metal-containing monomeric systems to those of enyne oligomers $(t$, from ref. 6$) . \bigcirc,|\gamma|$ of metal diacetylides; $\times,|\gamma|$ of metal phenyl acetylides. Solid line depicts an $L^{4}$ dependence

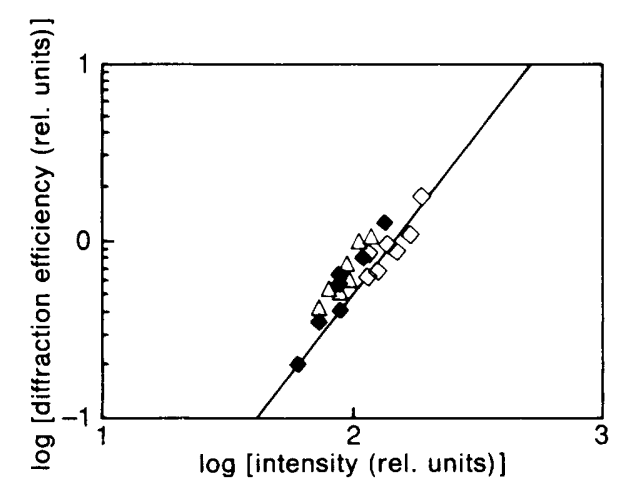

Fig. 5 Intensity dependence of the diffraction efficiency of chloroform $(\diamond)$, nickel polymer $(\triangle)$ and platinum polymer $(\diamond)$

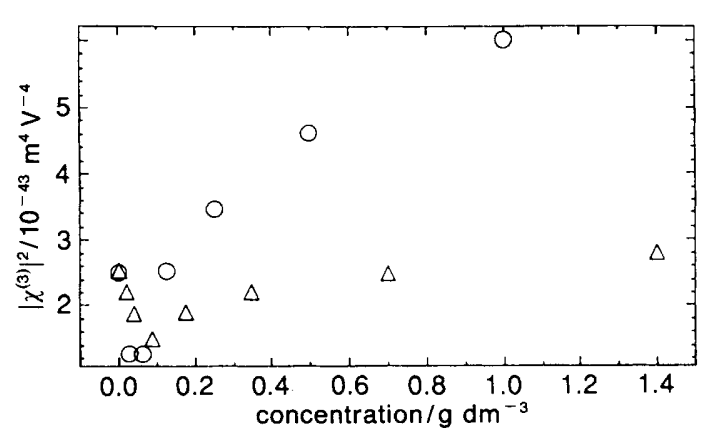

Fig. 6 Concentration dependence of $\left|\chi^{3}\right|^{2}$. $\bigcirc$, Nickel-substituted polymer; $\Delta$, platinum-substituted polymer standing of such effects are at present underway. An estimate of the 'infinite dilution' value of the hyperpolarisability can be made by fitting eqn. (3) to the low-concentration region of the curves. The values obtained from such a fit are tabulated in Table 1 for both the nickel and the platinum polymers as well as the values obtained from the same procedure applied to polydiacetylene solutions. ${ }^{23}$

As in the case of the monomers, the non-linear polarisability is greater for the nickel polymer than for the platinum. For both polymers, the magnitude of the molecular hyperpolarisability is larger than that of the corresponding polydiacetylene solutions. It should be noted, however, that the difference is not as pronounced, as is seen for the monomeric species. If the length dependence exhibited by the enyne oligomers $\left(L^{4}\right)$, also observed for thiophene oligomers ${ }^{8}$ applies for these metal-containing systems, then the polymers may be deemed to have an effective length of only 6-7 repeat units, whereas isopiestic molecular-weight determinations show that the number of repeat units is substantially in excess of this (e.g. for the platinum polymer, ca. 150 units). This compares to 7-10 effective repeat units for polydiacetylenes.

Qualitatively, the non-linearity of the metal-containing polymers behaves quite differently from that of polydiacetylene. The real component of the non-linearity is negative, in agreement with an extrapolation from the monomeric systems. In polydiacetylene solutions, the real component is positive. The non-linearity of polydiacetylene solutions is dominated by the influence of a two-photon resonance ${ }^{18,23}$ and the sign of the non-linearity is governed by the positioning of the laser wavelength with respect to this resonance. ${ }^{24}$ With the addition of this resonant enhancement, however, the susceptibility of the polydiacetylene solutions is still substantially less than those of the metal-containing polymers studied here.

\section{Conclusions}

Consideration of the non-linear optical susceptibilities of Group 10 metal alkynyls, measured in the transparency region, gives a clear indication of a strong involvement of the $\mathrm{d}$ orbital electrons in the $\pi$-conjugated electron system of the backbone. Non-linear susceptibilities of monomeric systems are substantially larger than those measured for short-chain enyne oligomers. Such an increase of the non-linearity with respect to organic analogues is seen also in the metal-containing polymers. This study of Group 10 transition metal containing compounds reveals clear dependences of the non-linearity on the metal which will lead to a further understanding of the role of the metal in the polarisability of the polymer electron backbone. 


\section{References}

1 W. M. Dennis, W. Blau and D. J. Bradley, Appl. Phys. Lett., $1985,47,200$

2 G. M. Carter, J. V. Hryniewicz, M. K. Thakur, Y. J. Chen and S. E. Meyler, Appl. Phys. Lett., 1986, 49, 998.

3 C. Sauteret, J-P. Hermann, R. Frey, F. Pradére, J. Ducuing, R. H. Baughman and R. R. Chance, Phys. Rev. Lett., 1976, 36, 956.

4 Non-linear Optical Effects in Organic Polymers, ed. J. Messier, F. Kajzar, P. N. Prasad and D. Ulrich, Kluwer, Nato ASI series, vol. 162, 1989

5 G. M. Carter, M. K. Thakur, Y. J. Chen and J. V. Hryniewicz, Appl. Phys. Lett., 1985, 47, 457.

6 H. J. Byrne, W. Blau, R. Giesa and R. C. Schulz, Chem. Phys. Lett., 1990, 167, 484.

7 W. P. Su, J. R. Schrieffer and A. J. Heeger, Phys. Rev. B, 1980, 22, 2099.

8 P. N. Prasad, in Nonlinear Optical Effects in Organic Polymers, ed. J. Messier, F. Kajzar, P. Prasad and D. Ulrich, Kluwer, Dordrecht, Nato ASI series, vol. 162, 1989, pp. 351-363.

9 J. Chatt and B. L. Shaw, J. Chem. Soc., 1960, 1718.

10 G. Calvin and G. E. Coates, J. Chem. Soc., 1960, 2008.

11 J. Chatt and B. L. Shaw, J. Chem. Soc., 1959, 4020.

12 N. Hagihara, H. Masai and K. Sonagoshira, J. Organomet. Chem. 1971, 26, 271.

13 S. B. Armitage, E. R. H. Jones and M. C. Whiting, J. Chem. Soc., 1951, 44.
14 N. Hagihara, S. Takahashi, K. Ohga and K. Sonagashira, J. Organomet. Chem., 1980, 188, 237.

15 N. Hagihara, S. Takahashi and K. Sonogashira, Macromolecules, $1977,10,879$.

16 H. J. Eichler, P. Gunter and D. W. Pohl, Laser Induced Gratings, Springer Series in Optical Sciences 50, Springer Verlag, New York, 1986.

17 H. J. Byrne, W. Blau and K. Y. Jen, Synth. Met., 1989, 32, 229.

18 J. M. Nunzi and D. Grec, J. Appl. Phys., 1987, 62, 2198.

19 P. D. Maker, R. W. Terhune and C. M. Savage, Phys. Rev. Lett., 1964, 12, 507.

20 C. Grossman, J. R. Heflin, K. Y. Wong, O. Zamani-Khamiri and A. F. Garito, in Nonlinear Optical Effects in Organic Polymers, ed. J. Messier, F. Kajzar, P. Prasad and D. Ulrich, Kluwer, Dordrecht, Nato ASI series, vol. 162, 1989.

21 Y. R. Shen, The Principles of Nonlinear Optics, Wiley-Interscience, New York, 1984.

22 (a) C. J. Cardin, D. J. Cardin, M. F. Lappert and K. W. Muir, J. Chem. Soc., Dalton Trans., 1978, 46; (b) H. Yamasaki and K. Aoki, quoted in N. Hagihara, K. Sonogashira and S. Takahashi, Adv. Polym. Sci., 1981, 41, 151.

23 H. J. Byrne and W. Blau, Synth. Met., 1990, 37, 231.

24 F. Kajzar and J. Messier, in Polydiacetylenes, ed. D. Bloor and R. R. Chance, Nato ASI Series, vol. 12, Martinus-Nijhoff, Dordrecht, 1985, pp. 325-333.

Paper 0/04326E; Received 25th September, 1990 